\title{
PRELIMINARY ENGINEERING OF A SEAWALL TO MITIGATE TYPHOON-INDUCED WAVE OVERTOPPING ALONG ROXAS BOULEVARD, MANILA
}

\author{
Eric C. Cruz, Institute of Civil Engineering, University of the Philippines, eccruz@upd.edu.ph \\ Jose Carlo Eric L. Santos, AMH Philippines, Inc., icels@amhphil.com \\ Laurenz Luigi Cruz, AMH Philippines, Inc., luigi.cruz@amhphil.com
}

\section{INTRODUCTION}

Roxas Boulevard (Fig. 1) is a crucial national road of the urban transport system of Metro Manila. The road is protected from the sea hazards of Manila Bay by Roxas Boulevard Seawall. This gravity-type seawall also protects the important recreational promenade and highvalue properties behind the wall. The seawall was overtopped several times by recent strong typhoons. In 2011, it collapsed after storm surges and waves generated by Typhoon Nesat overtopped it and caused substantial flooding of a vast urban area of Manila city just behind the seawall. It was rebuilt quickly after that but only to be overtopped again by severe storm tides and high waves from subsequent strong typhoons. A study was commissioned by the national public works agency DPWH to understand the causative processes and provide basis for suitable mitigating solutions against overtopping of the seawall. This study discusses the typhoon-induced hydrodynamics in Manila Bay and the preliminary engineering undertaken to design one of the engineering interventions that were recommended to mitigate seawall overtopping.

\section{METHODOLOGY}

The study involves simulative analyses of typhooninduced hydrodynamics along the Manila Bay coastline. Time histories and envelopes of storm tide levels during the historical typhoons were simulated via the numerical model ADCIRC. Storm waves generated during the critical time of typhoon passage were simulated by a nonlinear wave model. Storm tide levels and wave runup on the existing seawall were computed for various critical historical typhoons storm tides to obtain the nonovertopping water surface elevations on the seawall. hese results are then used to determine the adequacy of the existing crest elevations.

\section{RESULTS}

Figure 2 shows the tracks of 30 critical historical typhoons analyzed. Figure 3 shows the wave heights near the seawall due to Typhoon Fengshen 2008 showing wave penetration through the existing breakwaters. A synthesis of simulated storm tides and wave runup under existing conditions indicated the maximum water surface elevation along the seawall. This showed that the required minimum non-overtopping crest elevation (NOCE) of the seawall is above the existing crest by at least $2.2 \mathrm{~m}$. Several mitigation schemes were formulated based on various levels of overtopping risks and degree of engineering intervention. One of the schemes recommended is the raising of the seawall crest to the NOCE. The results of simulative analyses were used to design a preliminary plan layout and vertical section of the rehabilitated seawall, which were then iterated to obtain an improved non-overtopping seawall crest elevation. The associated level of risk was also determined based on a frequency analysis of the severe winds accompanying the critical typhoons during their closest approach to the seawall.

The paper is relevant to ICCE 2018 as it discusses an engineering approach to understand the causative processes, formulate various schemes to mitigate the overtopping hazards, and determine engineering parameters to serve the intended function of the schemes.

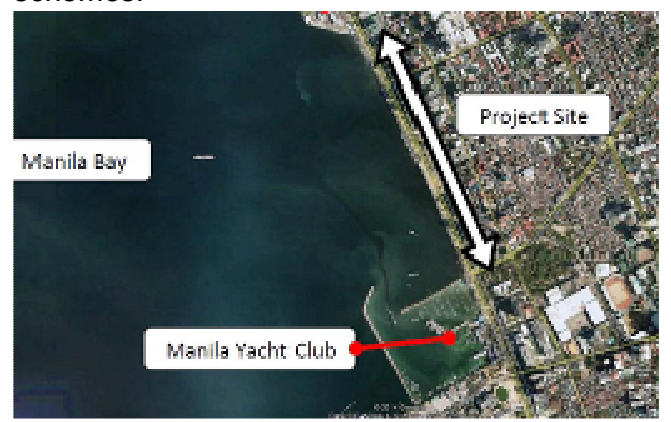

Figure 1 Project location

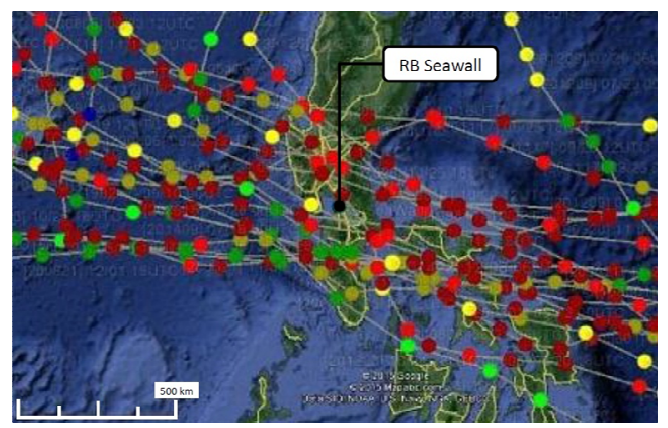

Figure 2 Tracks of historical typhoons

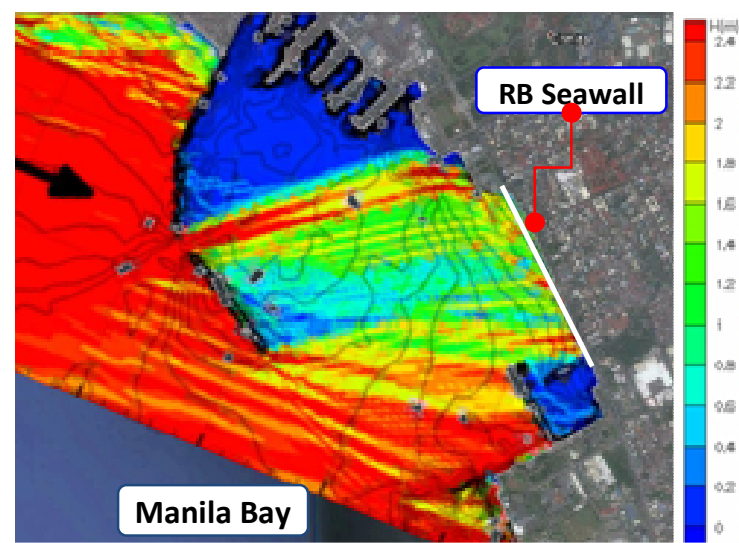

Figure 3 Bathymetry and structure layout 